\title{
THE ROLE OF KNOWLEDGE ACQUISITION IN ENHANCING KNOWLEDGE MANAGEMENT PROCESSES IN HIGHER EDUCATION INSTITUTIONS
}

\author{
Ibrahim MATAR (D, Jurgita RAUDELIŪNIENE் ${ }^{*} *$ \\ Department of Business Technologies and Entrepreneurship, Faculty of Business Management, \\ Vilnius Gediminas Technical University, Sauletekio al. 11, LT-10223 Vilnius, Lithuania
}

Received 28 February 2021; accepted 01 April 2021

\begin{abstract}
Purpose - this article investigates the impact of knowledge acquisition on the leading knowledge management processes such as knowledge storage, application, and creation in higher education institutions.

Research methodology - scientific literature review and hypotheses were used to develop the research model. The research data was collected from 202 academics from Lebanese higher education institutions. The structural questionnaire and structural equation modeling techniques were employed to test the research hypotheses.

Findings - the findings confirmed the knowledge acquisition process's leading role with the highest impact on knowledge creation and provided valuable insights for scientists in the knowledge acquisition field.

Research limitations - this study's results are primarily applicable in Lebanon and can't be generalized to other countries. Therefore, a further researcher should encompass diverse countries to generalize the findings on a global level.

Practical implications - the results emphasize more attention for higher education institutions' administration to focus on higher education institutions' knowledge management cycle, particularly on the knowledge acquisition process.

Originality/Value - in this study, the significant influence of knowledge acquisition on other knowledge management processes in the Lebanese higher education institutions has been revealed, as no prior research in Lebanon is found.
\end{abstract}

Keywords: knowledge management, knowledge management processes, Lebanon, higher education institutions, education.

JEL Classification: I2, C2, C3, D8.

Conference topic: Business Processes: Development, Digitalization, Social Responsibility.

\section{Introduction}

In the past twenty years, the Lebanese higher education institutions have gone through various changes and challenges (Hamzeh et al., 2019) to reach and achieve effective strategies that improve their quality education and facilitate them maintain the excellence of their educational programs (Vrontis et al., 2018). Therefore, Lebanese universities should direct these changes towards boosting their knowledge generation capabilities to proact and respond to the rapid social, economic, and technological transformations. The proper evaluation and implementation of the knowledge management cycle in Lebanese universities can help them efficiently monitor how knowledge is acquired, stored, and applied in their institutions.

Knowledge management generates the factors related to organizational success and, ultimately, the competitive advantage of knowledge acquisition (Rafiei et al., 2016). Therefore, analyzing its constituents would help academic administration to know how to execute their knowledge-related plans to suit institutions' mission and strategy. In Lebanon's context, there are limited studies that have handled knowledge management's impact on higher education institutions' performance. Besides, there is a lack of investigation related to knowledge acquisition's role in enhancing the knowledge management cycle in higher education institutions. Many scholars do not systematically analyze knowledge acquisition influence on knowledge management processes and organizational performance (Rehman \& Iqbal, 2020); most scientists focused on other knowledge management processes, such as the knowledge sharing

\footnotetext{
*E-mail: jurgita.raudeliuniene@vilniustech.lt
} 
process. As a result of existing gaps linked to the knowledge acquisition process, this study investigates the impact of knowledge acquisition on the leading knowledge management processes such as knowledge storage, application, and creation in higher education institutions. A scientific literature review, structured questionnaire, descriptive statistics, inferential statistics, and Partial Least Squares (PLS) structural equation modeling techniques were employed in this research.

This study's novelty stems from the fact that limited research assessed the influence of knowledge acquisition on knowledge management processes in Lebanon and the higher education sector. This research's practical implications are related to knowledge acquisition influence on three knowledge management processes in the Lebanese higher education sector and provide managerial implications for administration in higher education institutions.

The remaining sections in this study are structured as follows: the first section includes a scientific literature review about knowledge management in higher education institutions, knowledge management processes, and as a result of it, hypotheses are proposed. Next, the conceptual research framework is developed. In section two, the research methodology is presented. Finally, the last section includes the research results and discussion.

\section{The theoretical background of the study and hypotheses development}

In their continuous and endless pursuit, universities as learning organizations are always expected to actively engage in the formation and advancement of the knowledge economy (Adeinat \& Abdulfatah, 2019). The social pressure and need for qualified graduates who can adapt to job market changes necessitate that universities attentively acquire knowledge from their internal and external environment (Abeles, 2017). Higher education institutions design their study programs and curricula to fulfill the social needs and ensure that graduates can handle dynamic and complex careers. Thus, the acquisition and integration of the required knowledge and monitoring of such knowledge in higher education institutions can affect the performance of all institutional processes and the outputs of these knowledge-producing institutes. According to Shih and Tsai (2016), higher education institutions' capability to handle knowledge has to be highlighted so that research and teaching resources and all their operational processes can be efficaciously employed to advance their schools' success. A scientific literature review provides strong evidence that knowledge and knowledge management contribute to enhancing the excellence of organizations' activities, whether operating in public or private sectors.

Many scholars define knowledge management differently, and having a universal definition is quite challenging for knowledge management and knowledge management processes. According to Ahmed, Sheikh, and Akram (2018), knowledge management is defined as the coordination, formation of plans, and the design of systems and strategies that are aimed for the management of the intangible assets linked to knowledge are enhanced and effectively employed (Sadeghi Boroujerdi et al., 2019). Knowledge management processes refer to all the activities performed by organizations related to the acquisition, development, storage, sharing, and creation of knowledge (Intezari et al., 2017).

Based on J. Raudeliūnienè research results (Raudeliūnienè, 2017; Raudeliūnienè et al., 2020), knowledge management practice can consist of various knowledge management processes depending on organization-specific. After interviewing Lebanese higher education institutions administration, four knowledge management processes - knowledge acquisition, knowledge storage, knowledge application, and knowledge creation - are selected for deeper analysis. These four processes are actively applied in higher education institutions' research and teaching activities.

Knowledge acquisition refers to organizational practices and procedures designed to gather information from the organization's internal and external sources (Kianto et al., 2016). Knowledge acquisition conduct might comprise the attainment of design technology, revealing industrial know-how, potential customer data, and information about the most advanced operational methods necessary for the organization.

Knowledge storage refers to an organization's practices and strategies to maintain its knowledge base (Raj Adhikari, 2010). According to Levallet and Chan (2019), knowledge storage is a critical constituent of knowledge management. Its proper implementation can prevent the negative consequences of knowledge loss caused by unexpected situations in an organization, such as employee resignation, information and communication technology breakdowns.

Knowledge application refers to the executions of knowledge to institutions' processes and operations to create new services and product value for the society that an organization serves (Iqbal et al., 2019).

The knowledge creation process can be defined as continuous practices and processes that occur throughout individuals' interaction with their environments, resulting in the introduction of new knowledge with unique value to be utilized by individuals and organizations (Little \& Deokar, 2016).

Based on scientific literature review results, knowledge management processes can be considered as a holistic approach in organizations towards improving all organizational processes and functions. That leads to the optimization and excellence of their output reflected in their micro and macro environment where the mutual benefit between the organization and the society it serves is a reciprocal process.

Knowledge acquisition enables organizations to develop their competencies to create new knowledge and skills and elevate uniqueness and value (Choo, 2013). Also, the knowledge base view asserts that the knowledge acquisi- 
tion for organizations enables the creation of novel knowledge and allows organizations to improve their competitive advantage (Wahid et al., 2015). According to Fraihat and Samadi (2017), the "knowledge management process capability" starts with acquiring knowledge from the organization's inner and exterior sources. Dehghani and Akhavan (2017) highlighted that knowledge acquisition is an essential process in institutions because almost 90 percent of the organization's knowledge lies in its employees' minds and should be stored in the organizational memory.

Gaines (2013) stressed that knowledge acquisition, with its technological tools, has facilitated the creation, utilization, and access of knowledge in a way that has never been known in this millennia. Abker et al. (2019) emphasized that knowledge acquisition is crucial for new knowledge application as it permits replacing the existing content of the explicit and implicit knowledge possessed by the organization. Bloodgood (2019) stressed that organizations should assess knowledge acquisition to attain the necessary knowledge critical for their work processes and not increase their knowledge application costs caused by the uncritical knowledge acquired.

Based on the previous scholars' research results, this study's primary purpose is to test the influence of knowledge acquisition on knowledge storage, application, and creation in the Lebanese higher education institution context. As a result, the following hypotheses are proposed (Figure 1):

H1: Knowledge acquisition positively impacts knowledge storage;

H2: Knowledge acquisition positively impacts knowledge application;

H3: Knowledge acquisition positively impacts knowledge creation.

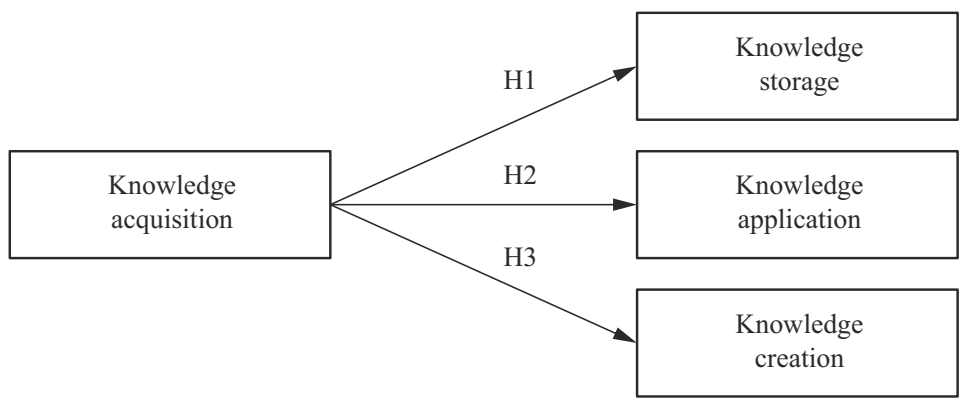

Figure 1. Research framework

(created by the authors)

The conceptual research framework includes the four latent constructs of this study: knowledge acquisition, knowledge storage, knowledge application, and knowledge creation. It shows the relationships analyzed in this study on how knowledge acquisition impacts knowledge storage, application, and creation where the hypothesized relationships are based on previous scholars' findings.

\section{Methodology}

Following the scientific literature review, the research hypotheses developed should be tested to answer this study's research purpose and question. The statistical analysis techniques employed to achieve this study's goal are descriptive statistics, inferential statistics, and PLS structural equation modeling technique. The data analysis was done through the 23rd version of Statistical Package for the Social Sciences (SPSS) and Smart PLS 3 software.

A survey was developed to measure this study's items, and a five-point Likert scale ranging from 1 (strongly disagree) to 5 (strongly disagree) was utilized. The survey was composed of three sections. Section 1 introduced the aim of this study. The second section included questions related to the demographic characteristics of the participants. The last section involved the 20 items linked to the four constructs of the study that were allocated as follows: five items for knowledge acquisition, five items for knowledge storage, five items for knowledge application, and five items for knowledge creation. All the statements included in the survey were new, and the survey was checked by four knowledge management experts so that the instrument's content and face validity are confirmed.

For a structural model test, the recommended sample size is five surveys for each item utilized or 10-20 surveys for every variable (Abu-Shanab \& Shehabat, 2018). Some scholars suggest a minimum sample size of 200 (Al Ahbabi et al., 2019). According to the total number of items utilized in the survey, the recommended sample size is 100 since the survey included 20 items to measure our constructs. The survey was sent to 400 Lebanese academics emails working in different Lebanese higher education institutions. Two hundred two respondents agreed to participate in this study, which yielded a $50.2 \%$ response rate. Therefore, the total responses received, which also makes the sample size of this study $\mathrm{N}=202$, are greater than the previous limits recommended by scholars. 


\section{Research results}

Common method bias and multicollinearity. Common method bias was assessed using Harman's single factor test, and the result was $37.681 \%$ which is less than the cut-off limit of $50 \%$. Also, collinearity is not an issue in this study since the value of the variance inflation factor for all the items was less than 3 , indicating a good result since scholars recommend it to be less than 5 (Akinwande et al., 2015).

Participants' information. Out of the 202 survey participants, 83 (41.1\%) were males, and $119(58.9 \%)$ were females. The respondents' age was distributed as follows: 40 (19.8\%) age was between 21 and 30 years, $98(48.6 \%)$ respondents' age was between 31 and 45 years, and the rest of respondents' age was above 46 years. The educational background of the participants involved 23 (11.4\%) respondents that hold a bachelor's degree, 114 (56.4\%) hold a master's degree, and 47 (23.3\%) have a Ph.D. degree. 64 (31.7\%) respondents have a professor, associate professor, or assistant professor status. $81(41.1 \%)$ of respondents have more than ten years of experience in the field (Table 1).

Table 1. Descriptive aspects of the Lebanese academics (created by the authors)

\begin{tabular}{|c|c|c|}
\hline Category & Frequency & Percentage \\
\hline \multicolumn{3}{|l|}{ Job role } \\
\hline Coordinator/Counselor/Advisor & 17 & $8.4 \%$ \\
\hline Dean/Associate Dean/Assistant Dean & 4 & $2.0 \%$ \\
\hline Director/ Associate Director/Assistant Director (academic department) & 11 & $5.4 \%$ \\
\hline Director/Associate Director/Assistant Director (administrative department) & 12 & $5.9 \%$ \\
\hline Lecturer/Assistant & 42 & $20.8 \%$ \\
\hline Manager/Administrator & 25 & $12.4 \%$ \\
\hline Professor/ Associate Professor/Assistant Professor & 64 & $31.7 \%$ \\
\hline Staff & 26 & $12.9 \%$ \\
\hline Rector/President/Chancellor & 1 & $0.5 \%$ \\
\hline \multicolumn{3}{|l|}{ Experience in the field (years) } \\
\hline$<3$ years & 30 & $14.9 \%$ \\
\hline $3-5$ years & 39 & $19.3 \%$ \\
\hline $6-10$ years & 52 & $25.7 \%$ \\
\hline $11-15$ years & 45 & $22.3 \%$ \\
\hline $16-20$ years & 25 & $12.4 \%$ \\
\hline $20+$ years & 11 & $5.4 \%$ \\
\hline
\end{tabular}

Measurement model evaluation. Using smart PLS software, confirmatory factor analysis was performed, and a rotated factor loadings matrix was generated to empirically test item allocation and ensure all the cross-loadings were less than the 0.6 recommended cut-off limit (Abu-Shanab \& Shehabat, 2018) (Table 2). In Table 2, the primary matrix is on the left shows all the items cross-loadings, and the cleansed matrix is on the right demonstrates the loadings relating to their original dimension.

The rotated factor loadings matrix confirmed that no item is problematic as all the cross-loadings were less than 0.6 , as well it has ensured that all the items should be included in the study. No item should be deleted since all indicator loadings exhibited in the cleansed matrix are greater than 0.7 .

The measurement model was evaluated using the same software as smart PLS. The Cronbach's alpha and composite reliability of all the constructs are above 0.8 , confirming the internal consistency and reliability among the constructs (Table 3). The average variance extracted (AVE) is above 0.5. All factors' loadings are greater than 0.7 (Figure 2), confirming convergent validity.

The measurement model indicated that all the constructs met the requirements of good indicator loading, convergent validity, composite reliability (CR), and discriminant validity, further analyzed below, to be used in the structural model.

Discriminant validity. Discriminant validity was confirmed using Fornell \& Larcker criterion and Heterotrait-Monotrait Ratio (HTMT). Research results (Table 4) show that the value of the AVE's square root, which is presented in diagonal and boldface, is above the rest of the inter-construct correlations (Hair et al., 2012).

The HTMT ratio for this study's four constructs is less than 0.9 (Table 5). Discriminant validity is achieved according to both methods applied, indicating that each construct is discriminately unique to the dimension that it intends to measure (Alyoubi et al., 2018). 
I. Matar, J. Raudeliūniene. 2021. The role of knowledge acquisition in enhancing knowledge management processes in higher education institutions

Table 2. Rotated factor loadings matrix (created by the authors)

\begin{tabular}{|l|c|c|c|c|c|c|c|c|}
\hline \multicolumn{7}{|c|}{ Cross loadings } & \multicolumn{5}{c|}{ Outer Loadings } \\
\hline \multicolumn{1}{|c|}{ ITEM } & KACQ & KAP & KCR & KST & KACQ & KAP & KCR & KST \\
\hline KACQ1 & 0.718 & 0.491 & 0.569 & 0.418 & 0.718 & & & \\
\hline KACQ2 & 0.814 & 0.469 & 0.524 & 0.463 & 0.814 & & & \\
\hline KACQ3 & 0.769 & 0.399 & 0.439 & 0.328 & 0.769 & & & \\
\hline KACQ4 & 0.786 & 0.365 & 0.419 & 0.404 & 0.786 & & & \\
\hline KACQ5 & 0.796 & 0.41 & 0.402 & 0.369 & 0.796 & & & \\
\hline KAP1 & 0.49 & 0.831 & 0.508 & 0.467 & & 0.831 & & \\
\hline KAP2 & 0.405 & 0.786 & 0.406 & 0.485 & & 0.786 & & \\
\hline KAP3 & 0.444 & 0.723 & 0.458 & 0.452 & & 0.723 & & \\
\hline KAP4 & 0.463 & 0.843 & 0.471 & 0.493 & & 0.843 & & \\
\hline KAP5 & 0.415 & 0.815 & 0.423 & 0.492 & & 0.815 & & 0.737 \\
\hline KCR1 & 0.526 & 0.441 & 0.737 & 0.41 & & & 0.804 & \\
\hline KCR2 & 0.534 & 0.509 & 0.804 & 0.465 & & & 0.731 & \\
\hline KCR3 & 0.373 & 0.371 & 0.731 & 0.303 & & & & 0.823 \\
\hline KCR4 & 0.482 & 0.442 & 0.823 & 0.39 & & & 0.803 & \\
\hline KCR5 & 0.458 & 0.438 & 0.803 & 0.37 & & & & 0.74 \\
\hline KST1 & 0.414 & 0.446 & 0.365 & 0.74 & & & & 0.817 \\
\hline KST2 & 0.46 & 0.469 & 0.414 & 0.817 & & & & 0.802 \\
\hline KST3 & 0.412 & 0.449 & 0.45 & 0.802 & & & 0.725 \\
\hline KST4 & 0.372 & 0.445 & 0.354 & 0.725 & & & 0.768 \\
\hline KST5 & 0.302 & 0.505 & 0.344 & 0.768 & & & \\
\hline
\end{tabular}

Table 3. Measurement model (created by the authors)

\begin{tabular}{|l|c|c|c|}
\hline \multicolumn{1}{|c|}{ Construct } & Cronbach's Alpha & Composite Reliability & Average Variance Extracted (AVE) \\
\hline KACQ & 0.836 & 0.884 & 0.604 \\
\hline KAP & 0.859 & 0.899 & 0.641 \\
\hline KCR & 0.84 & 0.886 & 0.61 \\
\hline KST & 0.83 & 0.88 & 0.595 \\
\hline
\end{tabular}

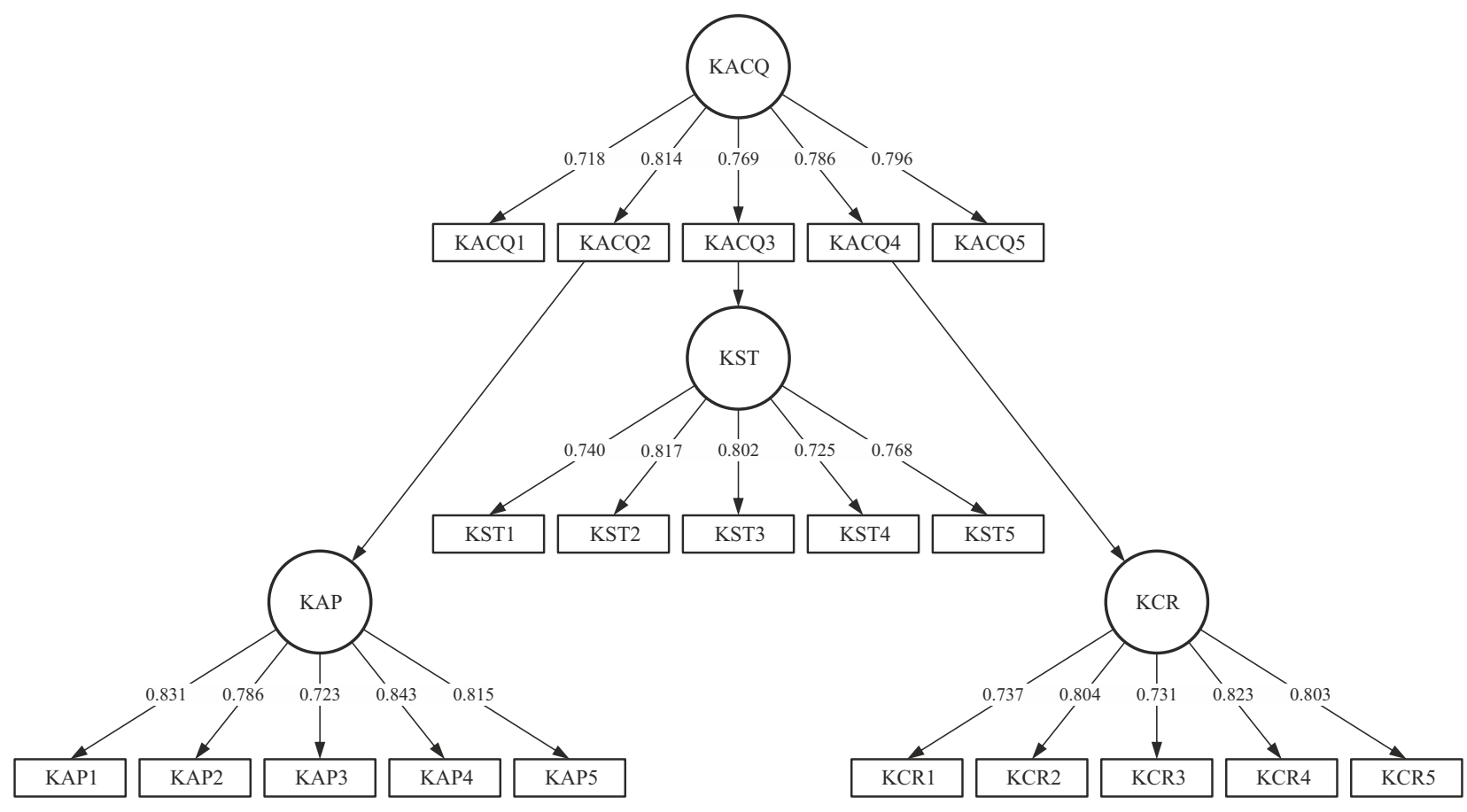

Figure 2. Measurement model factor loadings (created by the authors) 
Table 4. Correlation matrix and the square root of the AVE (created by the authors)

\begin{tabular}{|l|c|c|c|c|}
\hline Latent Variable & KACQ & KAP & KCR & KST \\
\hline KACQ & $\mathbf{0 . 7 7 7}$ & & & \\
\hline KAP & 0.557 & $\mathbf{0 . 8 0 1}$ & & \\
\hline KCR & 0.616 & 0.569 & $\mathbf{0 . 7 8 1}$ & \\
\hline KST & 0.516 & 0.597 & 0.504 & $\mathbf{0 . 7 7 1}$ \\
\hline
\end{tabular}

Note: KACQ: knowledge acquisition, KAP: knowledge application, KCR: knowledge creation, KST: knowledge storage.
Table 5. Heterotrait-Monotrait Ratio (HTMT) (created by the authors)

\begin{tabular}{|l|c|c|c|c|}
\hline & KACQ & KAP & KCR & KST \\
\hline KACQ & & & & \\
\hline KAP & 0.645 & & & \\
\hline KCR & 0.713 & 0.661 & & \\
\hline KST & 0.601 & 0.711 & 0.589 & \\
\hline
\end{tabular}

Table 6. Structural equation modeling results summary (created by the authors)

\begin{tabular}{|c|c|c|c|c|c|}
\hline Hypotheses & Path & Coefficient $(\beta)$ & T Statistics & P Values & Results \\
\hline H1 & KACQ $\rightarrow$ KST & 0.516 & 6.073 & $<0.001$ & Accepted \\
\hline H2 & KACQ $\rightarrow$ KAP & 0.557 & 7.751 & $<0.001$ & Accepted \\
\hline H3 & KACQ $\rightarrow$ KCR & 0.616 & 10.567 & $<0.001$ & Accepted \\
\hline
\end{tabular}

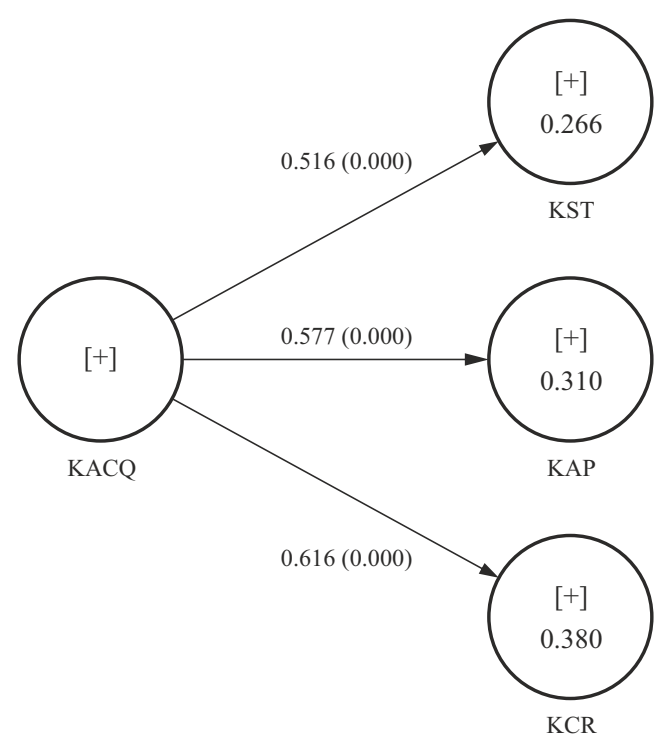

Figure 3. Structural model (created by the authors)

Structural model evaluation. The $\mathrm{R}^{2}$ values are all great than 0.2 (Figure 3), which supports the model's overall predictability, as they are all above the minimum recommended threshold of 0.2 in social sciences (Jilani et al., 2020). The Standardized Root Mean Square Residual (SRMR) is $0.077(<0.08)$; it supports that the model in this study has an acceptable model fit. Hence, the SRMR result, $\mathrm{R}^{2}$ values, reliability, and validity measures indicate that the study model is sufficient to assess the proposed hypothesized relationships as prior studies designate (Asiedu et al., 2020).

Hypotheses testing. Bootstrapping technique with resampling at $\mathrm{N}=5000$ cases was conducted to test the research hypotheses at a significance level less than $0.05(\mathrm{p}<0.05)$. The results indicate that knowledge acquisition positively and significantly influences all the knowledge management processes evaluated in this study: KACQ $\rightarrow$ KST $(\beta=0.516, \mathrm{t}=6.073, \mathrm{p}=<0.001), \mathrm{KACQ} \rightarrow \mathrm{KAP}(\beta=0.557, \mathrm{t}=7.751, \mathrm{p}=<0.001), \mathrm{KACQ} \rightarrow \mathrm{KCR}(\beta=0.616$, $\mathrm{t}=10.567, \mathrm{p}=<0.001$ ) (Table 6). As a result, the three hypotheses H1, H2, H3 that were proposed in this study are all accepted.

Research results reveal that knowledge acquisition has a substantial and positive influence on all knowledge management processes analyzed in this study and, most notably, the highest impact on knowledge creation. 


\section{Conclusions}

This study aimed to discover the effect of knowledge acquisition on knowledge storage, application, and creation. Based on research results, the knowledge acquisition process significantly influences knowledge management processes in Lebanese higher education institutions.

Scientific literature review and hypotheses were used to develop the research model. A structured questionnaire (survey) was designed and used for the data collection process, and 202 Lebanese academics participated in this study. The hypothesized relationships in the study were tested using the PLS structural equation modeling technique.

This study's results were consistent with previous scholars' findings (Wahid et al., 2015; Fraihat \& Samadi, 2017; Abker et al., 2019) about the distinctive role of knowledge acquisition. Knowledge acquisition represents $26.6 \%$ of the variance in knowledge storage $(\mathrm{R} 2=0.266), 31 \%$ in knowledge application $(\mathrm{R} 2=0.310)$, and noticeably $38 \%$ $(\mathrm{R} 2=0.380)$ in knowledge creation with the highest impact among other knowledge management processes with a path coefficient of $(\beta=0.616, p=<0.001)$.

This study contributes to theoretical and practical implications concerned with knowledge acquisition in several aspects. This research has identified positive and significant knowledge acquisition's influence on three knowledge management processes in higher education institutions, especially in the Lebanese higher education sector. In agreement with the study findings, the Lebanese university administration should focus on the knowledge acquisition process to enhance the whole knowledge management cycle and organizational performance. Lebanese higher education institutions should continuously motivate their administration and teaching staff to acquire more efficiently the knowledge and seek new effective and efficient knowledge acquisition strategies and techniques.

This study's primary limitation is that it was conducted in a narrow geographical scope and didn't encompass other similar countries or regions to Lebanon. Thus, the research results are mostly applicable for Lebanon higher education sector. Future research should consider including other countries in order to generalize the findings.

\section{Disclosure statement}

The authors do not have any competing financial, professional, or personal interests from other parties.

\section{References}

Abeles, T. P. (2017). What is the potential for disrupting the university? On the Horizon, 25(3), 209-214. https://doi.org/10.1108/OTH-02-2017-0006

Abker, A. Y., Mohamed, A. T., Ibrahim, S. B., \& Eltayeb, T. K. (2019). Knowledge acquisition and knowledge sharing as determines of organizational competitive advantage. American Journal of Business, Economics and Management, 7(1), 32-39.

Abu-Shanab, E., \& Shehabat, I. (2018). The influence of knowledge management practices on e-government success: A proposed framework tested. Transforming Government: People, Process and Policy, 12(3-4), 286-308. https://doi.org/10.1108/TG-02-2018-0016

Adeinat, I. M., \& Abdulfatah, F. H. (2019). Organizational culture and knowledge management processes: Case study in a public university. VINE Journal of Information and Knowledge Management Systems, 49(1), 35-53. https://doi.org/10.1108/VJIKMS-05-2018-0041

Ahmed, S., Sheikh, A., \& Akram, M. (2018). Implementing knowledge management in university libraries of Punjab, Pakistan. Information Discovery and Delivery, 46(2), 83-94. https://doi.org/10.1108/IDD-08-2017-0065

Akinwande, M. O., Dikko, H. G., \& Samson, A. (2015). Variance inflation factor: As a condition for the inclusion of suppressor variable(s) in regression analysis. Open Journal of Statistics, 5(7), 754-767. https://doi.org/10.4236/ojs.2015.57075

Al Ahbabi, S. A., Singh, S. K., Balasubramanian, S., \& Gaur, S. S. (2019). Employee perception of impact of knowledge management processes on public sector performance. Journal of Knowledge Management, 23(2), 351-373. https://doi.org/10.1108/JKM-08-2017-0348

Alyoubi, B., Hoque, M. R., Alharbi, I., Alyoubi, A., \& Almazmomi, N. (2018). Impact of knowledge management on employee work performance: Evidence from Saudi Arabia. The International Technology Management Review, 7(1), 13-24. https://doi.org/10.2991/itmr.7.1.2

Asiedu, M. A., Anyigba, H., Ofori, K. S., Ampong, G. O. A. \& Addae, J. A. (2020). Factors influencing innovation performance in higher education institutions. The Learning Organization, 27(4), 365-378. https://doi.org/10.1108/TLO-12-2018-0205

Bloodgood, J. M. (2019). Knowledge acquisition and firm competitiveness: The role of complements and knowledge source. Journal of Knowledge Management, 23(1), 46-66. https://doi.org/10.1108/JKM-09-2017-0430

Choo, C. W. (2013). Perspectives on managing knowledge in organizations. Knowledge Organization and Classification in International Information Retrieval, 205-220, 9374. https://doi.org/10.1300/J104v37n01_14

Dehghani, M., \& Akhavan, P. (2017). An experimental investigation of knowledge acquisition techniques. Journal of Management Development, 36(4), 493-514. https://doi.org/10.1108/JMD-07-2016-0132

Fraihat, B. A. M. A., \& Samadi, B. (2017). The effect of KM capabilities on the Performance of Jordanian Public Listed Companies. International Journal of Business and Social Research, 7(11), 9-20. https://doi.org/10.18533/ijbsr.v7i11.1077 
Gaines, B. R. (2013). Knowledge acquisition: Past, present and future. International Journal of Human Computer Studies, 71(2), 135-156. https://doi.org/10.1016/j.ijhcs.2012.10.010

Hair, J. F., Sarstedt, M., \& Ringle, C. M. (2012). An assessment of the use of partial least squares structural equation modeling in marketing research. Journal of the Academy of Marketing Science, 40, 414-433. https://doi.org/10.1007/s11747-011-0261-6

Hamzeh, W., Mershad, K., \& Vetohin, S. (2019). Integrating technology into higher education: A case study in Lebanon. Journal of Technology and Science Education, 9(3), 442-457. https://doi.org/10.3926/JOTSE.651

Intezari, A., Taskin, N., \& Pauleen, D. J. (2017). Looking beyond knowledge sharing: An integrative approach to knowledge management culture. Journal of Knowledge Management, 21(2), 492-515. https://doi.org/10.1108/JKM-06-2016-0216

Iqbal, A., Latif, F., Marimon, F., Sahibzada, U. F., \& Hussain, S. (2019). From knowledge management to organizational performance: Modelling the mediating role of innovation and intellectual capital in higher education. Journal of Enterprise Information Management, 32(1), 36-59. https://doi.org/10.1108/JEIM-04-2018-0083

Jilani, M. M. A. K., Fan, L., Islam, M. T., \& Uddin, M. A. (2020). The influence of knowledge sharing on sustainable performance: A moderated mediation study. Sustainability, 12(3), 908. https://doi.org/10.3390/su12030908

Kianto, A., Vanhala, M., \& Heilmann, P. (2016). The impact of knowledge management on job satisfaction. Journal of Knowledge Management, 20(4), 621-636. https://doi.org/10.1108/JKM-10-2015-0398

Levallet, N., \& Chan, Y. E. (2019). Organizational knowledge retention and knowledge loss. Journal of Knowledge Management, 23(1), 176-199. https://doi.org/10.1108/JKM-08-2017-0358

Little, T. A., \& Deokar, A. V. (2016). Understanding knowledge creation in the context of knowledge-intensive business processes. Journal of Knowledge Management, 20(5), 858-879. https://doi.org/10.1108/JKM-11-2015-0443

Rafiei, A., Akhavan, P., \& Hayati, S. (2016). Knowledge management in successful technology transfer (Case study: Iranian aerospace industries and knowledge-based centers). Aircraft Engineering and Aerospace Technology, 88(1), 178-188. https://doi.org/10.1108/AEAT-11-2013-0220

Raj Adhikari, D. (2010). Knowledge management in academic institutions. International Journal of Educational Management, 24(2), 94-104. https://doi.org/10.1108/09513541011020918

Raudeliūnienè, J. (2017). Organizacijos žiniu potencialo vertinimo aktualijos [Topicalities of the organization's knowledge potential assessment]. Technika. https://doi.org/https://doi.org/10.20334/2017-065-M

Raudeliūnienè, J., Albats, E., \& Kordab, M. (2020). Impact of information technologies and social networks on knowledge management processes in Middle Eastern audit and consulting companies. Journal of Knowledge Management, (ahead-of-print). https://doi.org/10.1108/JKM-03-2020-0168

Rehman, U. U., \& Iqbal, A. (2020). Nexus of knowledge-oriented leadership, knowledge management, innovation and organizational performance in higher education. Business Process Management Journal, 26(6), 1731-1758. https://doi.org/10.1108/BPMJ-07-2019-0274

Sadeghi Boroujerdi, S., Hasani, K., \& Delshab, V. (2019). Investigating the influence of knowledge management on organizational innovation in higher educational institutions. Kybernetes, 49(2), 442-459. https://doi.org/10.1108/K-09-2018-0492

Shih, W. L., \& Tsai, C. Y. (2016). The effects of knowledge management capabilities on perceived school effectiveness in career and technical education. Journal of Knowledge Management, 20(6), 1373-1392. https://doi.org/10.1108/JKM-12-2015-0515

Vrontis, D., El Nemar, S., Ouwaida, A., \& Shams, S. M. R. (2018). The impact of social media on international student recruitment: the case of Lebanon. Journal of International Education in Business, 11(1), 79-103. https://doi.org/10.1108/JIEB-05-2017-0020

Wahid, K. A., Numprasertchai, H., Sudharatna, Y., Laohavichien, T., \& Numprasertchai, S. (2015). The impact of knowledge sources on knowledge creation: A study in Thai innovative companies. Joint International Conference, 27(3), 237-250. 